\title{
The anti-Saccharomyces cerevisiae antibody assay in a province-wide practice: Accurate in identifying cases of Crohn's disease and predicting inflammatory disease
}

\author{
Brinderjit Kaila $M D^{1}$, Kenneth Orr PhD², Charles $N$ Bernstein $M D^{1,3}$
}

B Kaila, K Orr, CN Bernstein. The anti-Saccharomyces cerevisiae antibody assay in a province-wide practice: Accurate in identifying cases of Crohn's disease and predicting inflammatory disease. Can J Gastroenterol 2005;19(12):717-721.

OBJECTIVE: To determine the utility of the anti-Saccharomyces cerevisiae antibody (ASCA) ELISA test developed in Manitoba in 2001 in a population-wide sample referred from physicians across Manitoba in their investigation of patients with gastrointestinal symptoms.

METHODS: Patients whose serum was referred for ASCA testing in 2001 and 2002 were eligible for the present study. ELISA was performed by a technologist, blind to patient diagnoses. A single investigator contacted physicians to facilitate chart review. Data collected included demographics, final diagnoses and tests used to substantiate the final diagnosis.

RESULTS: Of 482 subjects identified, 410 charts were available for review and 29 of those were unavailable for follow-up or had incomplete charts. The present study population included Crohn's disease (CD, $n=114)$, ulcerative colitis $(n=74)$, indeterminate colitis $(n=31)$, celiac disease $(n=9)$, irritable bowel syndrome $(n=75)$, other diagnoses $(n=33)$ and no disease $(n=45)$. ASCA had a sensitivity of $37 \%$ (95\% CI 27.8 to 46.8 ) and specificity of $97 \%$ (95\% CI 93.8 to 98.6) for diagnosing $\mathrm{CD}$ and an odds ratio for a diagnosis of $\mathrm{CD}$ of 18.4 (95\% CI 8.2 to 41.3). The 47 ASCA-positive patients included the following diagnoses: $\mathrm{CD}=39$, ulcerative colitis $=3$, indeterminate colitis $=1$, celiac disease $=3$ and no disease $=1$. The likelihood of having an inflammatory disease if ASCA is positive was nearly 40 -fold. CONCLUSION: A positive ASCA test using this assay nearly clinches a diagnosis of some form of inflammatory intestinal disease, which is highly likely to be CD. In symptomatic patients, a positive ASCA test should encourage the clinician to pursue further investigations.

Key Words: Antineutrophil cytoplasmic antibody (ANCA); AntiSaccharomyces cerevisiae antibody (ASCA); Crohn's disease; Enzyme-linked immunosorbent assay (ELISA); Ulcerative colitis

Clinching a diagnosis of Crohn's disease or ulcerative colitis Can sometimes be challenging. Over the past decade, serological markers have emerged with the hope of helping clinicians differentiate Crohn's disease from ulcerative colitis. Taking into account the duration of colitis, the availability of colonoscopy and certain histological features, it is not usually difficult to make a diagnosis of chronic colitis. Determining
Le dosage des anticorps anti-Saccharomyces cerevisiae dans une pratique provinciale : Précis pour dépister les cas de maladie de Crohn et prédire les maladies inflammatoires

\begin{abstract}
OBJECTIF : Déterminer l'utilité du test ELISA des anticorps antiSaccharomyces cerevisiae (AASC) mis au point au Manitoba en 2001 auprès d'un échantillon de la population envoyé en consultation par des pédiatres du Manitoba dans le cadre de leur examen de patients souffrant de symptômes gastro-intestinaux.

MÉTHODOLOGIE : Les patients dont le sérum a été envoyé en vue de subir un test AASC en 2001 et 2002 étaient admissibles pour la présente étude. Le test ELISA a été exécuté par un technologue ne connaissant pas le diagnostic des patients. Un seul investigateur a communiqué avec les médecins afin de faciliter l'analyse des dossiers. Les données colligées incluaient des facteurs démographiques, le diagnostic définitif et les tests utilisés pour étayer ce diagnostic définitif.

RÉSULTATS : Des 482 sujets repérés, 410 dossiers étaient disponibles à l'analyse, dont 29 non disponibles au suivi ou incomplets. La population à l'étude incluait des cas de maladie de Crohn $(\mathrm{MC}, \mathrm{n}=114)$, de colite ulcéreuse $(n=74)$, de colite indéterminée $(n=31)$, de maladie cæliaque $(n=9)$ de syndrome du côlon irritable $(n=75)$, d'autres diagnostics $(n=33)$ et d'absence de maladie $(\mathrm{n}=45)$. L'AASC avait une sensibilité de $37 \%$ (95\% IC 27,8 à 46,8) et une spécificité de 97 \% (95 \% IC 93,8 à 98,6) pour le diagnostic de $\mathrm{MC}$ et un risque relatif rapproché de 18,4 pour diagnostiquer la MC (95 \% IC 8,2 à 41,3). Les 47 patients positifs à l'AASC étaient diagnostiqués comme suit : $\mathrm{MC}=39$, colite ulcéreuse $=3$, colite indéterminée $=1$, maladie cæliaque $=3$ et absence de maladie $=1$. La probabilité de souffrir d'une maladie inflammatoire en présence d'AASC positif était près de quarante fois plus élevée.

CONCLUSION : Un test d'AASC positif au moyen du dosage assure pratiquement le diagnostic d'une forme quelconque de maladie inflammatoire de l'intestin, très probablement une MC. Chez les patients symptomatiques, un test d'AASC positif devrait inciter le clinicien à approfondir ses examens.
\end{abstract}

whether the colitis is ulcerative or Crohn's can sometimes be more challenging. Antineutrophil cytoplasmic antibody with a perinuclear staining pattern by indirect immmunofluorescence (pANCA) testing for ulcerative colitis has a diagnosis sensitivity of $60 \%$ to $70 \%$ and a specificity of $85 \%(1-4)$. Its utility as a diagnostic marker for differentiating ulcerative colitis from Crohn's colitis is questionable following the publication of a

\footnotetext{
${ }^{1}$ Department of Internal Medicine, University of Manitoba; ${ }^{2}$ Department of Laboratory Medicine, University of Manitoba and the Saint Boniface

General Hospital Immunology Laboratory; ${ }^{3}$ University of Manitoba Inflammatory Bowel Disease Clinical and Research Centre, Winnipeg, Manitoba Correspondence: Dr Charles N Bernstein, \#804F - 715 McDermot Avenue, John Buhler Research Centre, Winnipeg, Manitoba R3E 3P4.

Telephone 204-789-3369, fax 204-789-3972, e-mail cbernst@cc.umanitoba.ca

Received for publication April 15, 2005. Accepted July 27, 2005
} 
report showing that up to $50 \%$ of patients with Crohn's colitis may be pANCA-positive (5).

Anti-Saccharomyces cerevisiae antibodies (ASCA) have been reported to be specific for Crohn's disease, although sensitivity is limited $(2-8)$. In earlier reports $(9,10)$ of phenotypic associations with ASCA, it was mostly associated with ileal disease, rather than isolated Crohn's colitis. Hence, with pANCA positivity associated with Crohn's colitis and ASCA positivity not associated with colonic disease, these antibodies were less promising as tools to differentiate between these two forms of colitis. Two groups assessed 'all comers' with Crohn's disease and ulcerative colitis and found that the combinations of ASCA-positive/pANCA-negative for Crohn's disease and ASCA-negative/pANCA-positive for ulcerative colitis had positive predictive values of over $90 \%(3,4)$. However, these promising results included many patients in whom serological findings added little to the securing of the diagnosis. Patients with small bowel disease, fistulas or perineal disease are thought to have a confirmed diagnosis of Crohn's disease based on those findings and these types of unequivocal cases bolstered the apparent high-utility value of these antibody combinations.

One group (11) studying the utility of these antibodies in pediatric patients with gastrointestinal complaints presented the argument that positive results of these antibodies would highly suggest that the patient had inflammatory bowel disease and would warrant the invasive investigations more readily pursued in adults. Crohn's disease is an entity where, at times, the diagnosis can be somewhat more elusive than ulcerative colitis. Ulcerative colitis can be more easily ruled out with normal lower endoscopy and colonic biopsies. However, in patients with difficult-to-diagnose abdominal pain or diarrheal disorders, any diagnostic clues may be helpful. More recently, in the setting where the usual diagnostic testing has failed to clinch a diagnosis, capsule endoscopy has been used with some success (12). Capsule endoscopy is a costly test and may be best reserved for those with a greater likelihood of having Crohn's disease.

In Manitoba, using serum collected from a tertiary referral centre, we developed an inexpensive and simple assay for measuring ASCA, and it proved to be highly specific for Crohn's disease (10). In our original smaller study (10), some subjects with celiac disease were ASCA-positive, and ASCApositive subjects did not have isolated colonic disease, hence the utility of ASCA as a necessary diagnostic adjunct was uncertain. Therefore, we undertook a retrospective study to determine the utility of ASCA in all patients in whom it was ordered from across the province of Manitoba in the first two years of assay availability.

\section{METHODS}

ASCA are immunoglobulin $\mathrm{G}$ and immunoglobulin A antibodies that recognize the mannose sequences in the cell wall of $S$ cerevisiae strain Su 1 (Saccharomyces uvarum). An ELISA, using crude mannan as antigen, identifies ASCA (7). In 2000, an ELISA to determine antibodies to $S$ cerevisiae was developed in Winnipeg, Manitoba at the Saint Boniface General Hospital Immunology Laboratory, which serves as the provincial reference laboratory for specialized immune antibody testing for clinical purposes. Sera were randomly selected from a serum bank established for studies of inflammation and inflammatory markers from the University of Manitoba Inflammatory Bowel Disease Clinical and Research
Centre. A standard ELISA was run using $0.2 \mathrm{~g}$ of mannan from $\mathrm{S}$ cerevisiae (Sigma Diagnostics, USA) (10). A positive result was determined to be greater than 15 binding units, which was at least four standard deviations from the mean of normal controls. The assay had a sensitivity of $53 \%$ and a specificity of $96 \%$ for diagnosing Crohn's disease when compared with all others, and in comparing Crohn's disease with ulcerative colitis, the sensitivity was $60 \%$ and the specificity was $100 \%$.

In 2001, physicians from across the province could refer serum for ASCA testing to the Saint Boniface General Hospital Immunology Laboratory. The laboratory conducted ASCA testing blind to any clinical information. All subjects from Manitoba, both adult and pediatric, whose serum had been referred for ASCA testing in 2001 and 2002, were eligible for the present study. ELISA was performed by a technologist, blind to patient diagnoses. Clinicians making the final diagnoses were not blind to the ASCA test results. A single investigator contacted physicians to facilitate chart review. Data collected included demographics, final diagnoses, Crohn's disease phenotype, tests used to substantiate final diagnosis and pANCA results (for those in whom it was ordered). If patients had fistulizing disease, strictures and inflammation, the patients were categorized as having fistulizing disease (ie, by the most advanced lesion present). Furthermore, fistulizing disease referred to enteric fistulas independent of the presence or absence of perineal disease.

Sensitivity, specificity and odds ratios were calculated. Fisher's exact test, with two-tailed $\mathrm{P}$ values, was used to compare proportions, and Student's $t$ test was used to compare means with standard deviations. The present study was approved by the University of Manitoba Research Ethics Board.

\section{RESULTS}

Of the 482 patients identified, 410 (85\%) were reviewed (the remaining 72 had physicians who could not be contacted either because of relocation, retirement or death). Of the 410 patients, 29 were unavailable for follow-up or had incomplete charts, leaving 381 charts for analysis. A single investigator (BK) gathered all the data except for one case record, which was completed by the personal physician.

There were 114 patients with Crohn's disease, 74 with ulcerative colitis, 31 with indeterminate colitis, nine with celiac disease, 75 with irritable bowel syndrome (IBS), 33 with other diagnoses and 45 with no disease (Table 1). There were 215 males and 166 females, and there was no difference in diagnoses between the sexes except that IBS was more common among females (Table 1). The mean age of patients in each diagnostic category was similar except patients with 'other' diagnoses tended to be older (Table 1 ). In terms of type of physician referring patients for ASCA testing, $82.7 \%$ of patients were referred by either an adult or pediatric gastroenterologist, $14.7 \%$ were referred by a surgeon, $2.9 \%$ were pediatricians and $0.3 \%$ were family physicians. Several investigations were used to substantiate patient diagnoses (Table 2).

\section{ASCA results}

There were 47 patients who were ASCA-positive and, of these, 39 (83\%) had Crohn's disease, three (6\%) had ulcerative colitis, one (2\%) had indeterminate colitis, three $(6 \%)$ had celiac disease and one (2\%) had no disease (Table 1). Serological data based on diagnoses are summarized in Table 3. Of note, 39 of 114 patients (34\%) with Crohn's disease were ASCA-positive. Furthermore, there was no significant difference 
TABLE 1

Demographics and anti-Saccharomyces cerevisiae antibodies (ASCA) positivity by disease diagnoses

\begin{tabular}{|c|c|c|c|c|c|c|c|}
\hline & $\begin{array}{l}\text { Crohn's disease } \\
\qquad(n=114)\end{array}$ & $\begin{array}{l}\text { Ulcerative colitis } \\
\qquad(n=74)\end{array}$ & $\begin{array}{l}\text { Indeterminate colitis } \\
\qquad(n=31)\end{array}$ & $\begin{array}{l}\text { Celiac disease } \\
\qquad(n=9)\end{array}$ & $\begin{array}{l}\text { Irritable bowel } \\
\text { syndrome }(n=75)\end{array}$ & $\begin{array}{l}\text { Other } \\
(n=33)\end{array}$ & $\begin{array}{c}\text { No disease } \\
(n=45)\end{array}$ \\
\hline Females/males & $60 / 54$ & $38 / 36$ & $15 / 16$ & $8 / 1^{*}$ & $48 / 27^{*}$ & $19 / 14$ & $27 / 18$ \\
\hline $\begin{array}{l}\text { Age, years } \\
\qquad(\text { mean } \pm S D)\end{array}$ & $32.3 \pm 17.4$ & $36.8 \pm 20.8$ & $40.3 \pm 22.8$ & $35.3 \pm 14.3$ & $35.4 \pm 17.0$ & $52.8 \pm 23.0^{\dagger}$ & $39.0 \pm 21.6$ \\
\hline ASCA-positive & 39 & 3 & 1 & 3 & 0 & 0 & 1 \\
\hline
\end{tabular}

${ }^{\star} P<0.04$ for Crohn's disease versus celiac disease and for Crohn's disease versus irritable bowel syndrome for percentage of females; ${ }^{\dagger} P<0.0001$ for Crohn's disease versus noninflammatory diagnosis other than irritable bowel syndrome (other) for mean age

TABLE 2

Main investigations used to substantiate diagnoses

\begin{tabular}{lccccccc}
\hline & $\begin{array}{c}\text { CD } \\
(\mathbf{n = 1 1 4})\end{array}$ & $\begin{array}{c}\text { UC } \\
(\mathbf{n}=\mathbf{7 4})\end{array}$ & $\begin{array}{c}\text { Cel } \\
(\mathbf{n}=\mathbf{9})\end{array}$ & $\begin{array}{c}\text { IC } \\
(\mathbf{n}=\mathbf{3 1})\end{array}$ & $\begin{array}{c}\text { IBS } \\
(\mathbf{n}=\mathbf{7 5})\end{array}$ & $\begin{array}{c}\text { Other } \\
(\mathbf{n}=\mathbf{3 3})\end{array}$ & $\begin{array}{c}\text { ND } \\
(\mathbf{n}=\mathbf{4 5})\end{array}$ \\
\hline Colonoscopy & 107 & 74 & 6 & 31 & 45 & 22 & 20 \\
lleoscopy & 81 & 46 & 6 & 22 & 31 & 15 & 9 \\
EGD & 45 & 13 & 9 & 12 & 35 & 20 & 16 \\
Duodenal & 14 & 5 & 9 & 2 & 7 & 10 & 4 \\
$\quad$ biopsy & & & & & & & \\
SBFT & 74 & 20 & 3 & 18 & 33 & 6 & 13 \\
CT abd & 28 & 9 & 1 & 3 & 15 & 4 & 9
\end{tabular}

CD Crohn's disease; Cel Celiac disease; CT abd Computed tomography of the abdomen; EGD Esophagogastroduodenoscopy; IBS Irritable bowel syndrome; IC Indeterminate colitis; ND No disease; SBFT Small bowel followthrough; UC Ulcerative colitis

in ASCA positivity by sex; however, ASCA-positive patients were significantly younger (Table 3 ). The site of the disease in the present study population among Crohn's disease patients who were ASCA-positive was as follows: $37 \%$ with small bowel only, $31 \%$ with colon only and 38\% with both small and large bowel involvement (Table 4). Among the Crohn's patients, 79 had isolated inflammatory disease (ASCA-positive in 32.9\%), 28 had fistulizing disease (ASCA-positive in 39.3\%) and seven had stricturing disease (ASCA-positive in 42.5\%) (Table 4). Of 22 subjects with perineal disease, ASCA was positive in 29.2\%. The difference in ASCA positivity based on disease phenotype was not significant $(\mathrm{P}=0.46)$.

Comparing mean ASCA serological values in Crohn's disease patients according to disease location (Table 5), the difference was significant between small bowel disease and isolated colonic disease $(\mathrm{P}=0.004)$, as well as between combined small and large bowel disease and isolated colonic disease $(\mathrm{P}=0.003)$. The difference in the mean ASCA values between patients with isolated small bowel disease and those with combined small and large bowel disease was not significant $(\mathrm{P}=0.15)$. There was no statistically significant difference in mean ASCA values in patients with inflammatory disease compared with those patients who had fistulas or strictures $(\mathrm{P}=0.18)$ (Table 5).

Only 92 of the Crohn's disease patients' charts had documentation of a smoking history (Table 4). Of 33 Crohn's disease patients with positive smoking histories, $10(30.3 \%)$ were ASCA-positive and, of 59 nonsmokers, 23 (39.0\%) were ASCA-positive $(\mathrm{P}=0.41)$.

Comparing Crohn's disease with all other diagnoses, the sensitivity was $36.8 \%$ (95\% CI 27.8 to 46.8 ) and specificity was 96.9\% (95\% CI 93.8 to 98.6) (Table 6) (eight Crohn's disease patients were deemed to be borderline on ASCA assessment). Similarly, comparison between Crohn's disease and ulcerative
TABLE 3

Anti-Saccharomyes cerevisiae antibodies (ASCA)-positive versus ASCA-negative patients

\begin{tabular}{lcc}
\hline & $\begin{array}{c}\text { ASCA-positive } \\
\mathbf{n = 4 7}\end{array}$ & $\begin{array}{c}\text { ASCA-negative } \\
\mathbf{n = 3 3 4}\end{array}$ \\
\hline Female (\%) & 53.2 & 56.6 \\
Mean age \pm SD & $28.9 \pm 17.0$ & $38.5 \pm 21.0^{*}$ \\
Crohn's disease (\%) (n=114) & 34.2 & 65.8 \\
Other inflammatory & 6.1 & 93.9 \\
disease (\%) & & \\
Noninflammatory disease & 0.7 & 99.3 \\
(IBS/other disease/ND) (\%) & & \\
\hline
\end{tabular}

${ }^{*} P<0.001$ for ASCA-positive versus ASCA-negative; IBS Irritable bowel syndrome; ND No disease

colitis revealed a sensitivity of $36.8 \%$ (95\% CI 27.8 to 46.8 ) and a specificity of $95.9 \%$ (95\% CI 87.7 to 98.9$)$. Contrasting the presence of any inflammatory bowel disease (Crohn's disease, ulcerative colitis, indeterminate colitis and celiac disease) with no disease, IBS and other diagnoses demonstrated a sensitivity of $21.1 \%$ (95\% CI 16.0 to 27.2 ), specificity of 99.3\% (95\% CI 95.8 to 100.0$)$ and an odds ratio of $39.9(95 \%$ CI 5.43 to 292.5). Notably, 33\% of the patients with celiac disease were ASCA-positive.

\section{pANCA}

Of the 381 patients in the present study, only 280 were tested for pANCA. Locally, it is not standard practice to order both ASCA and pANCA testing on each patient, and which tests are ordered is at the discretion of the individual physician. Nonetheless, the ANCA test was specific for ulcerative colitis and was positive in 24 of 61 (39.3\%) ulcerative colitis patients and only one of 79 patients (1.3\%) with Crohn's disease, three of $22(13.6 \%)$ with indeterminate colitis and none of five patients with celiac disease, none of 58 patients with IBS, none of 17 with other diagnoses and none of 38 with no disease.

\section{DISCUSSION}

The present study shows that our assay, with a strict cut-off for a positive diagnosis (at more than four standard deviations from the mean of normals), has a very high specificity for Crohn's disease. When there are non-Crohn's disease cases that are positive, they invariably have some form of inflammatory disease. The performance of our assay in a larger sample size was less sensitive than initially reported. However, the specificity remained very high for Crohn's disease. Sensitivity levels of approximately $40 \%$ have been reported $(13,14)$ from two other large assay comparability studies with commentary suggesting that for different ASCA assays, sensitivity and specificity are invariably inversely related. The impact of the 


\section{TABLE 4}

Disease location, pathology, smoking history and antiSaccharomyces cerevisiae antibodies (ASCA) serology in patients with Crohn's disease

\begin{tabular}{lcc}
\hline & ASCA-positive & ASCA-negative \\
\hline Disease site, $\mathrm{n}(\%)$ & & 16 \\
Small bowel only & $10(38.5)$ & $35^{\star}$ \\
Colon only & $15(30.0)$ & 24 \\
Small bowel + colon & $14(36.8)$ & 17 \\
Perineal $^{*}$ & $7(29.2)$ & \\
Disease behaviour, $\mathrm{n}(\%)$ & & 53 \\
Inflammatory & $26(32.9)$ & 4 \\
Stricturing & $3(42.9)$ & 17 \\
Fistulizing & $11(39.3)$ & 23 \\
Smokers, $\mathrm{n}(\%)$ & $10(30.3)$ & 36 \\
Nonsmokers, $\mathrm{n}(\%)$ & $23(39.0)$ &
\end{tabular}

${ }^{*}$ Perineal includes anyone with perineal disease regardless of other sites of disease

\section{TABLE 5}

Anti-Saccharomyces cerevisiae antibodies (ASCA) values according to Crohn's disease phenotype

\begin{tabular}{ll}
\hline & Average ASCA serological value \\
\hline Disease site & \\
Small bowel $(n=10)$ & $83 \pm 46.0^{*}$ \\
Both $(n=14)$ & $58 \pm 32.1$ \\
Colon $(n=15)$ & $26 \pm 5.8$ \\
Disease behaviour & \\
Inflammatory $(n=24)$ & $45 \pm 33.1^{\dagger}$ \\
Stricturing $(n=7)$ & $56 \pm 42.5$ \\
Fistulizing $(n=10)$ & $67 \pm 47.6$ \\
Perineal $(n=7)$ & $62 \pm 45.3$ \\
\hline
\end{tabular}

*Small bowel site versus small bowel and colon (both), $P=0.15$; small bowel versus colon, $P=0.004$; ${ }^{\dagger}$ Inflammatory versus stricturing and fistulizing combined, $P=0.18$

differences in sample populations, a province-wide survey of all samples assessed over a two-year period versus samples assessed from a tertiary referral clinic, upon the sensitivity of the assay is uncertain.

Although the mean ASCA value was higher in those patients with isolated small bowel disease versus isolated colonic or combined small bowel and colonic disease, a new finding in the present study is that ASCA was also positive in cases with isolated colonic disease and, in fact, ASCA did not correlate with any one disease location. This is different from our initial study $(10)$ and from data from other centres $(9,15)$. ASCA was positive in $37 \%$ with any small bowel disease, in $31 \%$ with colonic disease and in $38 \%$ with both small and large bowel involvement. This raises the possibility that ASCA may still be useful in differentiating Crohn's colitis from ulcerative colitis. This would best be studied by a prospective analysis of indeterminate colitis using our assay. A recent study (16) of indeterminate colitis from Belgium and France did not show that ASCA testing was a strong predictor of cases ultimately becoming definite Crohn's disease.

ASCA was positive in 33\% of patients with celiac disease. In Holland, celiac disease was associated with ASCA positivity in $43 \%$ of 37 patients (17). Occasionally, patients with ulcerative colitis were also ASCA-positive in the present study. Celiac disease can be associated with microscopic colitis.
TABLE 6

Accuracy of anti-Saccharomyces cerevisiae antibodies (ASCA) assay*

\begin{tabular}{lccc}
\hline Test $^{\dagger}$ & CD vs all & CD vs UC & $\begin{array}{c}\text { CD/UC/IC/Cel vs } \\
\text { ND/Other/IBS }\end{array}$ \\
\hline Sensitivity & $36.8(27.8-46.8)^{\star}$ & $36.8(27.8-46.8)$ & $21.1(16.0-27.2)$ \\
Specificity & $96.9(93.8-98.6)$ & $95.9(87.7-98.9)$ & $99.3(95.8-100.0)$ \\
PPV & $83.0(68.7-91.9)$ & $92.9(79.4-98.1)$ & $97.9(87.3-99.9)$ \\
NPV & $79.1(74.1-83.3)$ & $51.1(42.5-59.7)$ & $46.4(40.9-52.0)$ \\
OR & $18.4(8.21-41.26)$ & $13.58(4.01-46.06)$ & $39.85(5.43-292.5)$ \\
\hline
\end{tabular}

*The calculation of these data do not include eight cases of Crohn's disease (CD) whose ASCA assay was considered borderline; ${ }^{\dagger}$ All tests $95 \% \mathrm{Cl}$. Cel Celiac disease; IBS Irritable bowel syndrome; IC Indeterminate colitis; ND No disease; NPV Negative predictive value; Other Noninflammatory diagnosis other than inflammatory bowel syndrome; PPV Positive predictive value; UC Ulcerative colitis; vs Versus

Hence, it is unclear whether a positive ASCA test represents an indication of small bowel pathology or of a colonic defect (or both).

A limitation of the present study is that ASCA results were available to the clinicians who ordered them and, hence, the ultimate diagnoses were not made blind to the ASCA (or ANCA) results. The gold standard diagnosis of Crohn's disease was made on the basis of standard endoscopic ( $94 \%$ underwent colonoscopy) and radiological (89\% underwent computed tomography of the abdomen or small bowel follow-through) tests, and surgical data or other hallmarks of Crohn's disease such as fistulas, perineal disease or granulomas, and all final diagnoses used for study purposes were those confirmed by the researchers. Of those in the diagnostic categories of IBS, other or no diagnoses, the researchers had to be satisfied that sufficient testing was pursued to either rule out Crohn's disease, or that normal blood tests or other markers did not warrant further invasive testing. While it is possible that a known ASCA result could influence the decision to further pursue Crohn's disease testing, in 2001 and 2002 the true utility of our ASCA assay was not known to the ordering physicians. Because the present study was conducted in 2004 (the chart review and assessment of outcomes), there was more time for those in the non-Crohn's disease categories to present with new or other diagnostic features. The ASCA assay in this current assessment was less sensitive than when the assay was developed (10), suggesting that more subjects with Crohn's disease had negative ASCA tests. Nonetheless, it remains plausible that the diagnostic testing in some subjects was influenced once the ASCA result was known, which could affect the specificity we are reporting.

In assessing the value of ASCA, it is important to determine the indication for ordering the test. For instance, with currently available data, it does not seem to be a strong test to confirm a diagnosis in a patient labelled as having indeterminate colitis. Given the low sensitivity of our ASCA assay, it is likely not a good test for asymptomatic screening or for subclinical disease. ASCA was positive in up to $25 \%$ of healthy first-degree relatives of Crohn's disease patients, suggesting that these antibodies may be markers for subclinical disease in families, or simply a marker of a genetic predisposition (18-22). Hence, positive ASCA results will have to be interpreted cautiously in patients who have first degree relatives with Crohn's disease. However, in symptomatic patients, as in the present study, a positive ASCA result may be highly suggestive of an inflammatory process. We are not suggesting that ASCA can 
replace the current gold standards of imaging and mucosal biopsy; however, a positive ASCA result should alert clinicians to investigate these patients further, because our results indicate a 40 -fold chance of some inflammatory disease (Crohn's disease, ulcerative colitis, indeterminate colitis or celiac disease). Perhaps positive ASCA results can identify which patients with gastrointestinal symptoms should undergo more invasive testing, particularly in children where invasive investigations are less desirable. ANCA testing only identified inflammatory disease, most of which was ulcerative colitis, and could be used to screen for inflammatory disease. The converse, however, of not pursuing invasive testing if ASCA or ANCA testing is negative, is not supported by the data because both of these tests have relatively low sensitivity levels. So, if positive ASCA and ANCA testing encourages more invasive investigations, and negative testing cannot necessarily negate

\section{REFERENCES}

1. Duerr RH, Targan SR, Landers CJ, Sutherland LR, Shanahan F. Antineutrophil cytoplasmic antibodies in ulcerative colitis: Comparison with other colitides/diarrheal illnesses. Gastroenterology 1991;100:1590-6.

2. Ruemmele FM, Targan SR, Levy G, Dubinsky M, Braun J, Seidman EG. Diagnostic accuracy of serological assays in pediatric inflammatory bowel disease. Gastroenterology 1998;115:822-9.

3. Quinton JF, Sendid B, Reumaux D, et al. Anti-Saccharomyces cerevisiae mannan antibodies combined with antineutrophil cytoplasmic autoantibodies in inflammatory bowel disease: Prevalence and diagnostic role. Gut 1998;42:788-91

4. Peeters M, Joossens S, Vermeire S, Vlietinck R, Bossuyt X, Rutgeerts P. Diagnostic value of anti-Saccharomyces cerevisiae and antineutrophil cytoplasmic autoantibodies in inflammatory bowel disease. Am J Gastroenterol 2001;96:730-4.

5. Vasiliauskas EA, Plevy SE, Landers CJ, et al. Perinuclear antineutrophil cytoplasmic antibodies in patients with Crohn's disease define a clinical subgroup. Gastroenterology 1996;110:1810-9.

6. Main J, McKenzie H, Yeaman GR, et al. Antibody to Saccharomyces cerevisiae (baker's yeast) in Crohn's disease. BMJ 1988;297:1105-6.

7. Sendid B, Colombel JF, Jacquinot PM, et al. Specific antibody response to oligomannosidic epitopes in Crohn's disease. Clin Diagn Lab Immunol $1996 ; 3: 219-26$

8. Rutgeerts P, Vermeire S. Clinical value for the detection of antibodies in the serum for diagnosis of inflammatory bowel disease. Gastroenterology 1998;115:1006-9.

9. Vasiliauskas EA, Kam LY, Karp LC, Gaiennie J, Yang H, Targan SR. Marker antibody expression stratifies Crohn's disease into immunologically homogeneous subgroups with distinct clinical characteristics. Gut 2000;47:487-96.

10. Bernstein CN, Orr K, Blanchard JF, Sargent M, Workman D. Development of an assay for antibodies to Saccharomyces cerevisiae: Easy, cheap and specific for Crohn's disease. Can J Gastroenterol 2001;15:499-504

11. Dubinsky MC, Ofman JJ, Urman M, Targan SR, Seidman EG. Clinical utility of serodiagnostic testing in suspected pediatric inflammatory bowel disease. Am J Gastroenterol 2001;96:758-65. more invasive investigations, what place in the diagnostic algorithm might these tests have? The data suggest that positive ASCA (and ANCA) tests results are sufficiently likely to be associated with inflammatory disease and that they should trigger further testing to wholly rule in or out inflammatory disease in cases where there is some ambivalence about pursuing invasive or more costly diagnostic testing, or where some initial tests provide ambiguous or uncertain results.

While the concept of using ASCA to determine which patients should have further invasive investigations is not new (11), we believe it is worthy of further consideration.

ACKNOWLEDGEMENTS: Dr Charles N Bernstein is supported in part by a Canadian Institutes of Health Research Investigator Award and by a Crohn's and Colitis Foundation of Canada Research Scientist Award.

12. Mow WS, Lo SK, Targan SR, et al. Initial experience with wireless capsule enteroscopy in the diagnosis and management of inflammatory bowel disease. Clin Gastroenterol Hepatol 2004;2:31-40.

13. Vermeire S, Joossens S, Peeters M, et al. Comparative study of ASCA (anti-Saccharomyces cerevisiae antibody) assays in inflammatory bowel disease. Gastroenterology 2001;120:827-33.

14. Sandborn WJ, Loftus EV Jr, Colombel JF, et al. Evaluation of serologic disease markers in a population-based cohort of patients with ulcerative colitis and Crohn's disease. Inflamm Bowel Dis 2001;7:192-201.

15. Klebl FH, Bataille F, Bertea CR, et al. Association of perinuclear antineutrophil cytoplasmic antibodies and anti-Saccharomyces cerevisiae antibodies with Vienna classification subtypes of Crohn's disease. Inflamm Bowel Dis 2003;9:302-7.

16. Joossens S, Reinisch W, Vermeire S, et al. The value of serologic markers in indeterminate colitis: A prospective follow-up study. Gastroenterology 2002;122:1242-7.

17. Damoiseaux JG, Bouten B, Linders AM, et al. Diagnostic value of antiSaccharomyces cerevisiae and antineutrophil cytoplasmic antibodies for inflammatory bowel disease: High prevalence in patients with celiac disease. J Clin Immunol 2002;22:281-8.

18. Sendid B, Quinton JF, Charrier G, et al. Anti-Saccharomyces cerevisiae mannan antibodies in familial Crohn's disease. Am J Gastroenterol 1998;93:1306-10.

19. Sutton CL, Yang H, Li Z, Rotter JI, Targan SR, Braun J. Familial expression of anti-Saccharomyces cerevisiae mannan antibodies in affected and unaffected relatives of patients with Crohn's disease. Gut 2000;46:58-63.

20. Vermeire S, Peeters M, Vlietinck R, et al. Anti-Saccharomyces cerevisiae antibodies (ASCA), phenotypes of IBD, and intestinal permeability: A study in IBD families. Inflamm Bowel Dis 2001;7:8-15.

21. Annese V, Andreoli A, Andriulli A, et al. Familial expression of antiSaccharomyces cerevisiae mannan antibodies in Crohn's disease and ulcerative colitis: A GISC study. Am J Gastroenterol 2001;96:2407-12.

22. Seibold F, Stich O, Hufnagl R, Kamil S, Scheurlen M. AntiSaccharomyces cerevisiae antibodies in inflammatory bowel disease: A family study. Scand J Gastroenterol 2001;36:196-201. 


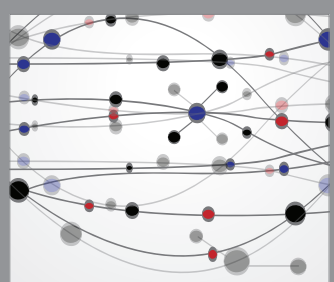

The Scientific World Journal
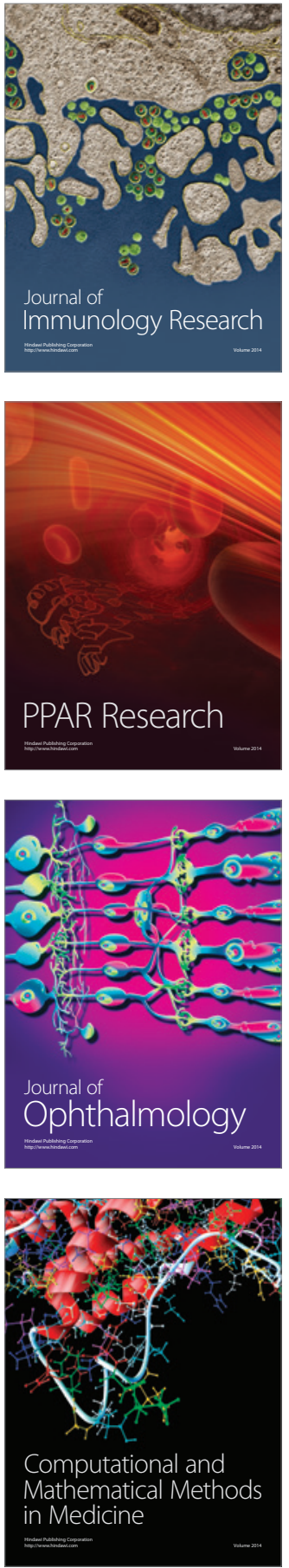

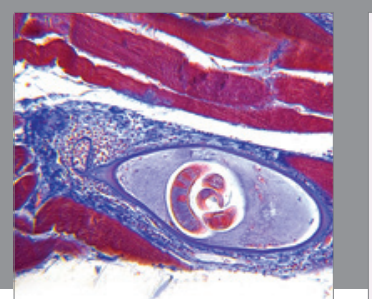

Gastroenterology Research and Practice

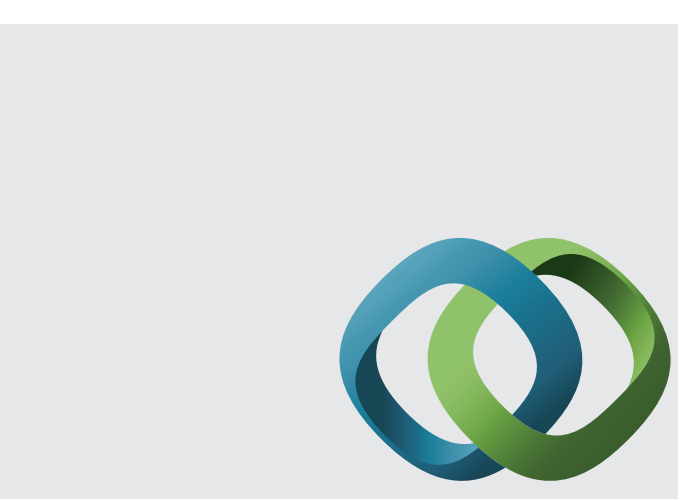

\section{Hindawi}

Submit your manuscripts at

http://www.hindawi.com
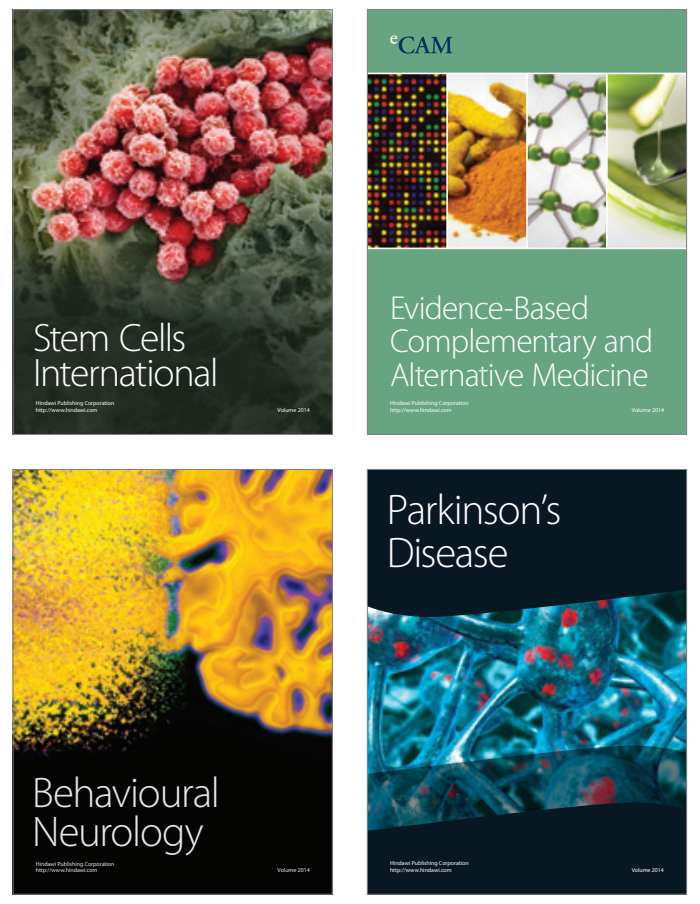
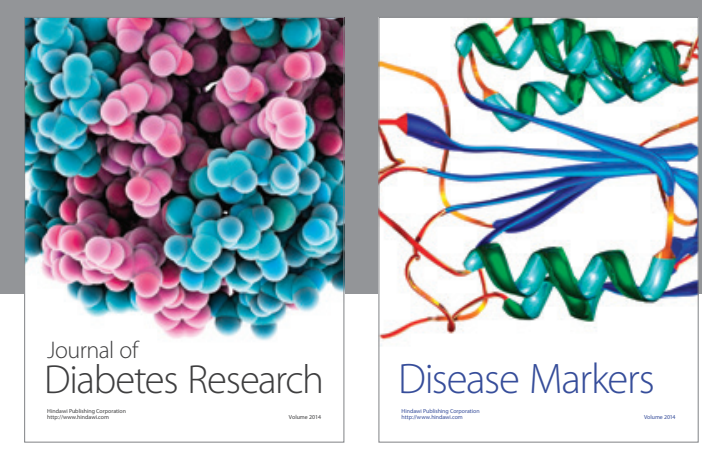

Disease Markers
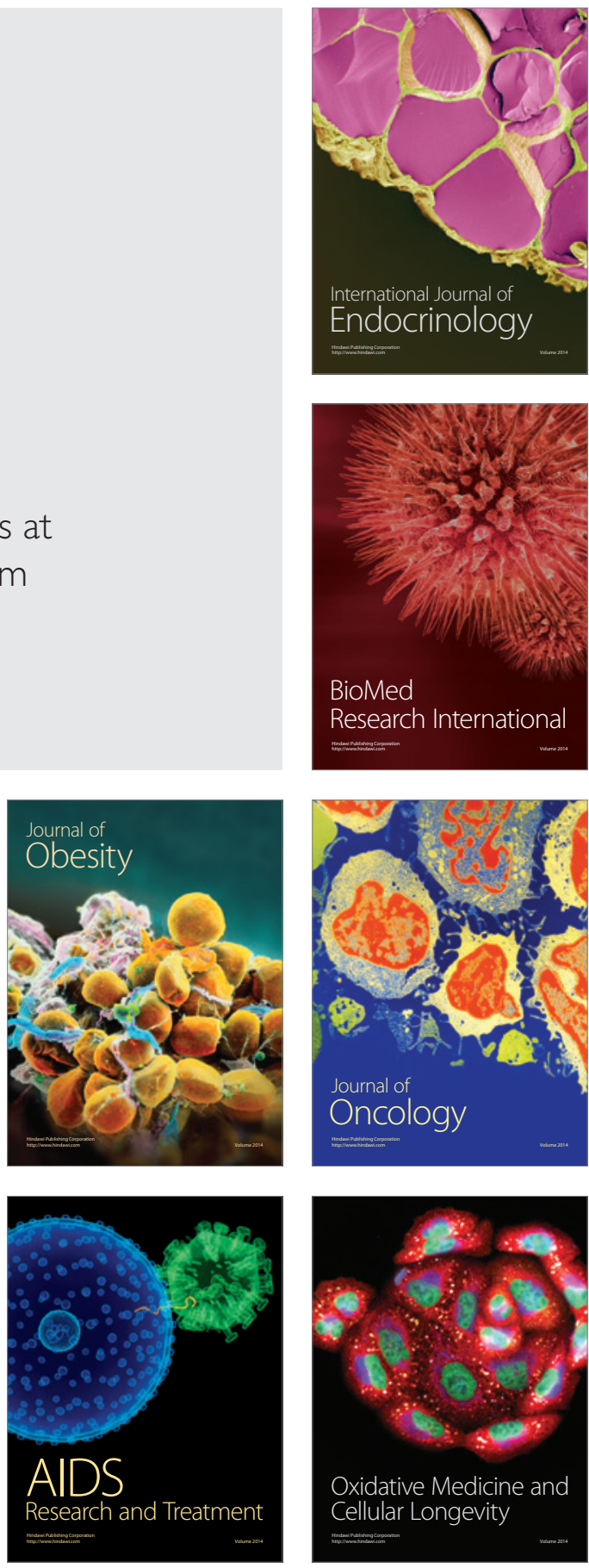